\title{
PENGARUH MOTIVASI DAN LINGKUNGAN KERJA TERHADAP KINERJA PEGAWAI DINAS PENDIDIKAN KABUPATEN INDRAMAYU
}

The Effect of Motivation and Work Environment on the Performance of Indramayu District Education Office Staff

\section{Ike Septiani (1), Sumardi HR ${ }^{(2)}$, Suryanti ${ }^{(3)}$}

Ikeseptiani13@gmail.com; Sumardi.hr@unwir.ac.id; suriantife@unwir.ac.id Manajemen FE, Universitas Wiralodra

\begin{abstract}
Abstrak
Penelitian ini bertujuan untuk mengetahui seberapa besar pengaruh Motivasi dan Lingkungan Kerja terhadap Kinerja pegawai Dinas Pendidikan Kabupaten Indramayu. Metode penelitian yang digunakan yaitu metode deskriptif dan metode asosiatif. Populasi Dinas Pendidikan Kabupaten Indramayu sebanyak 105 dan sampel yang diperoleh dari hasil perhitungan slovin sebanyak 83 pegawai. Data yang dikumpulkan menggunakan instrument penilaian kinerja yang dijawab oleh Pimpinan/Kepala Dinas dan instrument responden pegawai yang berkaitan dengan Motivasi dan Lingkungan Kerja. Hasil penelitian menunjukan bahwa penilaian Kinerja pegawai Dinas Pendidikan oleh
\end{abstract}

\section{PENDAHULUAN}

Sumber daya manusia paling menentukan dalam pencapaian tujuan perusahaan. Karena sumber daya manusia termasuk unsur dari kekuatan daya saing bangsa, untuk itu sumber daya manusia dituntut menjadi unggul dan professional dalam kerjanya demi kemajuan dan pencapaian tujuan perusahaan. Sumber daya manusia adalah suatu elemen yang sangat penting yang dimiliki perusahaan, dan mempunyai peran utama dalam kegiatan yang dilakukan perusahaan. Setiap perusahaan harus dapat mengoptimalkan dan mengelola sumber daya yang dimilikinya. Keberhasilan dalam mengelola organisasi untuk mencapai tujuan sangat dibutuhkan dukungan dari sumber daya manusia. Faktor sumber daya pimpinan tergolong kategori sangat baik, Motivasi yang diterima pegawai dikategorikan baik, Lingkungan Kerja disekitar pegawai sangat baik. Tetapi pengaruh yang didapat dari Motivasi terhadap Kinerja tergolong kategori rendah, pengaruh Lingkungan Kerja terhadap Kinerja tergolong rendah, dan pengaruh Motivasi dan Lingkungan Kerja terhadap Kinerja tergolong rendah. Dari keseluruhan yang dilihat bahwa masih kurangnya peningkatan antara Kinerja, Motivasi dan Lingkungan Kerja.

Kata kunci : Motivasi, Lingkungan Kerja dan Kinerja

manusia menjadi faktor kunci keberhasilan organisasi dalam pencapaian tujuan.

Dinas Pendidikan Kabupaten Indramayu merupakan dinas yang bertanggung jawab untuk melaksanakan pembangunan di bidang pendidikan yang mengacu pada peningkatan sumber daya manusia. Oleh karena itu, para pegawai diwajibkan mempunya kinerja yang dapat membantu tujuan dari Dinas Pendidikan yang dapat dilihat dari indikator dalam kinerja yaitu kualitas, kuantitas, waktu, penekanan biaya, pengawasan, dan hubungan antar karyawan.

Kualitas kerja di Dinas Pendidikan ini dapat dibilang kurang karena pegawai tidak memiliki motivasi yang tinggi dalam belajar maupun bekerja, kuantitas kerja di Dinas Pendidikan masih kurang karena dalam 
Ike Septiani, Sumardi HR, Suryanti

menjalakan pekerjaanya tidak dapat bertanggungjawab sehingga tugas-tugas yang diberikan tidak dapat diselesaikan tepat waktu, ketepatan waktu pegawai dalam bekerja hanya beberapa orang yang mengikuti aturan jam kerja pegawai, pegawai Dinas Pendidikan dapat dibilang mampu menekankan anggaran agar tidak terjadinya pemborosan sehingga kinerja pegawai dianggap cukup baik, di Dinas Pendidikan adanya pengawasan akan pekerjaan yang dilakukan pegawai, selanjutnya hubungan antar pegawai, hubungan ini dikaitkan dengan hubungan antar perseorangan yang dapat diukur dari kerja sama antara pegawai yang satu dengan pegawai yang lain, di Dinas Pendidikan kita dapat melihat langsung bahwa adanya hubungan antar pegawai dan pegawai saling membantu satu sama lain.

Banyak Faktor yang mempengaruhi kinerja menurut Kasmir (2016:188) ada 13 faktor diantaranya; kemampuan, pengetahuan, rancangan kerja, kepribadian, motivasikerja, kepemimpianan, gaya kepemimpinan, budaya organisasi, kepuasan kerja, lingkungan kerja, loyalitas, komitmen serta disiplin kerja

Peneliti sebelumnya telah membuktikan bahwa ; Motivasi berpengaruh Terhadap Kinerja sesuai dengan jurnal yang disusun oleh Olivia Theodora dengan judul Pengaruh Motivasi Kerja Terhadap Kinerja Karyawan Pt.Sejahtera Motor Gemilang (Jurnal Agora, Vol 3, No 2, 2015), Lingkungan Kerja di Dinas Pendidikan Kabupaten Indramayu. Sesuai dengan jurnal yang disusun oleh Nela Pima Rahmawanti, Bambang Swasto, dan Arik Prasetya. Dengan Judul Pengaruh Lingkungan Kerja Terhadap Kinerja Karyawan (Studi Pada Karyawan Kantor Pelayanan Pajak Pratama Malang Utara) (Jurnal Administrasi bisnis (JAB), Vol 8, No 2, 2014), Lingkungan Kerja terhadap Kinerja di Dinas Pendidikan Kabupaten Indramayu. Sesuai dengan jurnal yang disusun oleh Audrey Josephine dan Dhyah Harjanti. Dengan judul Pengaruh Lingkungan Kerja Terhadap Kinerja Karyawan Pada Bagian Produksi Melalui Motivasi Kerja Sebagai Variabel Intervening Pada PT. Trio Corporate Plastic (Tricopla) (Jurnal Agora, Vol 5, No 3, 2017).

\section{TINJAUAN PUSTAKA}

1. Kinerja

Menurut Kasmir (2016 : 182), menyatakan bahwa : "Kinerja adalah hasil kerja dan perilaku kerja yang telah dicapai dalam menyelesaikan tugas - tugas dan tanggung jawab yang diberikan dalam suatu periode tertentu". Kalimat diatas memiliki arti, kinerja merupakan hasil kerja seorang pegawai dalam menyelesaikan tugas yang diberikan dalam periode tertentu.

Menurut Prawirosentoni (1999) dalam Lijan Poltak Sinambela (2016 : 481), menyatakan bahwa : "Kinerja adalah hasil kerja yang dapat dicapai oleh seseorang atau sekelompok orang dalam suatu 
Ike Septiani, Sumardi HR, Suryanti

organisasi, sesuai dengan wewenang dan tanggung jawab masing-masing, dalam rangka upaya mencapai tujuan organisasi bersangkutan secara legal, tidak melanggar hukum dan sesuai dengan moral dan etika”. Kalimat diatas memiliki arti, kinerja adalah hasil kerja yang dapat dicapai oleh seseorang sesuai dengan tanggungjawab masing-masing dalam rangka upaya mencapai tujuan oraganisasi dan melaksanakan pekerjaannya sesuai dengan moral dan etika.

Menurut Rivai dan Basri (2005) dalam Lijan Poltak Sinambela (2016 : 482), menyatakan bahwa: "Kinerja adalah hasil atau tingkat keberhasilan seseorang atau keseluruhan selama periode tertentu dalam melaksanakan tugas dibandingkan dengan berbagai kemungkinan, seperti standar hasil kerja, target atau sasaran atau kriteria yang telah ditentukan lebih dahulu dan telah disepakati bersama". Kalimat diatas memiliki arti, kinerja adalah tingkat keberhasilan seseorang dalam melaksanakan tugas sesuai dengan yang telah disepakati bersama.

Berdasarkan pendapat para ahli diatas dapat disintesiskan bahwa, kinerja adalah perilaku kerja yang telah dicapai dalam menyelesaikan tanggungjawab dalam rangka upaya mencapai tujuan yang dapat dicapai oleh seseorang selama periode tertentu dengan berbagai kemugkinan seperti standar hasil kerja, target atau saasaran atau kriteria yang telah ditentukan. Menurut Kasmir (2016 : 208-209), indikator kinerja adalah sebagai berikut : 1 . Kualitas (mutu) 2 Kuantitas (jumlah) 3. Waktu (jangka waktu) 4. Penekanan biaya 5. Pengawasan 6. Hubungan antar karyawan

2. Motivasi

Menurut Wexley \& Yukl (1997) (dalam As'ad,2001) dalam Edy Sutrisno (2017 : 110-111), menyatakan bahwa: "Motivasi adalah pemberian atau penimbulan motif atau dapat pula diartikan sebagai hal atau keadaan menjadi motif. Jadi, motivasi adalah sesuatu yang menimbulkan semangat atau dorongan kerja". Kalimat diatas memiliki arti, motivasi adalah suatu pemberian motif yang menimbulkan semangat kerja seseorang untuk melakukan suatu tindakan.

Menurut Robbins (2008) dalam Muhammad Burso (2018 : 50), menyatakan bahwa : "Motivasi merupakan kemauan untuk menggunakan usaha tingkat tinggi untuk tujuan organisasi, yang dikondisikan oleh kemampuan usaha untuk memenuhi beberapa kebutuhan individu". Kalimat diatas memiliki arti, motivasi merupakan suatu kemauan usaha untuk tujuan organisasi yang dikondisikan oleh kemampuan dari beberapa individu.

Menurut Hasibuan (1999) dalam Edy Sutrisno (2017 : 111), menyatakan bahwa: "Motivasi adalah pemberian daya 
Ike Septiani, Sumardi HR, Suryanti

penggerak yang mencapai kegairahan kerja seseorang, agar mereka mau bekerja sama, bekerja efektif, dan terintegrasi dengan segala daya upayanya untuk mencapai kepuasan". Kalimat diatas memiliki arti, motivasi adalah pemberian daya penggerak yang mencapai kegairahan kerja seseorang agar mau bekerja sama dalam upaya untuk mencapai kepuasan.

Berdasarkan pendapat para ahli diatas dapat disintesiskan bahwa, motivasi adalah suatu pemberian motif yang dapat menggerakan semangat dan gairah kerja seseorang agar dapat bekerja dengan usaha tingkat tinggi untuk tujuan organisasi, maka seorang pegawai harus mau bekerja sama, bekerja efektif, dan terintegrasi untuk mencapai suatu kepuasan. Menurut sintesis para ahli diatas maka dapat dikemukakan indikator motivasi adalah mampu : 1. Bekerja sama 2. Bekerja efektif 3. Terintegrasi 4. Semangat kerja

3. Lingkungan Kerja

Menurut Kasmir (2018:192), menyatakan bahwa : "Lingkungan kerja adalah suasana atau kondisi disekitar lokasi tempat bekerja dapat berupa ruangan, layout, sarana dan prasarana, serta hubungan kerja dengan sesama rekan kerja”. Kalimat diatas memiliki arti, lingkungan kerja adalah suasana disekitar tempat kerja yang berupa ruangan, layout, sarana dan prasarana, serta hubungan kerja dengan sesama rekan kerja.
Menurut Edy Sutrisno (2017:118), menyatakan bahwa: "Lingkungan kerja adalah keseluruhan sarana dan prasarana kerja yang ada disekitar karyawan yang sedang melakukan pekerjaan yang dapat mempengaruhi pelaksanaan pekerjaan”. Kalimat diatas memiliki arti, lingkungan kerja adalah keseluruhan sarana dan prasarana yang ada disekitar karyawan dan dapat mempengaruhi pekerjaannya.

Menurut Sedarmayati (2011:2), menyatakan bahwa: "Lingkungan kerja adalah keseluruhan alat perkakas dan bahan yang dihadapi, lingkungan sekitarnya dimana sesorang bekerja, metode kerjanya, serta pengaturan kerjanya baik sebagai perseorangan maupun sebagai kelompok". Kalimat diatas memiliki arti, lingkungan kerja adalah keseluruhan alat perkakas dan bahan yang ada dilingkungan sekitar pegawai dalam bekerja baik dalam metode kerjanya, serta pengaturan kerjanya baik perseorangan maupun kelompok.

Berdasarkan pendapat para ahli diatas dapat disintesiskan bahwa, lingkungan kerja adalah suasana kerja yang ada disekitar tempat bekerja baik itu berupa sarana dan prasarana, alat perkakas, serta hubungan kerja dengan sesama rekan kerja agar dapat mempengaruhi pegawai juga mampu bekerja sesuai metode kerja dan pengaturan kerjanya. Menurut sintesis para ahli diatas maka dapat dikemukakan 
Ike Septiani, Sumardi HR, Suryanti

indikator lingkungan kerja yaitu: 1. Sarana dan Prasaran 2. Alat perkakas 3. Hubungan kerja 4. Suasana kerja

\section{METODE PENELITAN}

Metode penelitian yang digunakan adalah metode Deskriptif Assosiatif dengan teknik analisis data menggunakan Analisis Korelasi Ganda. Data yang dipergunakan adalah data primer berupa seperangkat format instrument penelitian yang terdiri dari angket penilaian kinerja dan tanggapan pegawai yang dipergunakan untuk mengumpulkan data; variabel kinerja, motivasi dan lingkungan kerja yang diisi oleh pegawai dan kepala Dinas Pendidikan Kabupaten Indramayu.

\section{HASIL DAN PEMBAHASAN}

Populasi pegawai Dinas Pendidikan Kabupaten Indramayu berjumlah 105 pegawai, dengan menggunakan teknik Simple Random Sampling peneliti menggunakan rumus slovin maka jumlah sampel yang digunakan sebanyak 83 pegawai.

Adapun variabel dan indikator pada penelitian ini tergambar pada Tabel 2.

Table 2.Variabel indikator penelitian

\begin{tabular}{llll}
\hline ariabel & Indicator & Skala & referensi \\
\hline inerja ( Y ) & Kualitas (mutu) & Likert & Kasmir (2016) \\
& Kuantitas (jumlah) & & \\
& Waktu (jangka waktu) & & \\
& Penekanan biaya & & \\
& Pengawasan & & \\
& Hubungan & antar & \\
\hline lotivasi $\left(\mathrm{X}_{1}\right)$ & Bekerja sama & Likert & Sintesis para Ahli \\
& Bekerja efektif & & Wexley \& Yukl (1997) \\
& Terintegrasi & & $\mathbf{( 2 0 1 7 : 1 1 0 ) , ~ R o b b i n s ~ ( 2 0 0 8 ) ~}$ \\
& Semangat kerja & & (2018:50), Hasibuan (1999) \\
& & & $(\mathbf{2 0 1 7 : 1 1 1 )}$ \\
\hline ingkungan & Sarana dan Prasaran & Likert & Sintesis para Ahli \\
erja $\left(\mathrm{X}_{2}\right)$ & Alat perkakas & & Kasmir (2018:192), Edy \\
& Hubungan kerja & & Sutrisno (2017:118), \\
& Suasana kerja & Sedarmayati (2011:2) \\
\hline
\end{tabular}

Valid tidaknya butir instrumen diuji terlebih dahulu signifikansi koefisien korelasinya dengan cara membandingkan dengan nilai $\mathrm{r}_{\text {tabel. }}$. Kriteria keputusan ditetapkan bahwa butir instrumen dikatakan valid jika $r$ observasi lebih besar dari pada $\mathrm{r}_{\text {tabel }} 0.576$ dan 0.707 seperti yang tergambar pada Tabel 3.

Tabel 3 Validitas variabel

\begin{tabular}{lllllll}
\hline \multirow{2}{*}{ Variabel } & \multirow{2}{*}{$\mathrm{R}_{\text {critical }}$} & $\mathrm{R}_{\text {count }}$ & \multicolumn{3}{c}{ Nilai } & \multirow{2}{*}{ Exp. } \\
\cline { 3 - 6 } & $\mathrm{R}_{\text {below }}$ & $\mathrm{R}_{\text {upper }}$ & Min & Max & \\
\hline Kinerja & 0.576 & 0.684 & 0.835 & 36 & 46 & Valid \\
\hline Motivasi & 0.707 & 0.726 & 0.792 & 34 & 42 & Valid \\
\hline Lingkungan kerja & 0,707 & 0,826 & 0,872 & 35 & 39 & Valid \\
\hline
\end{tabular}

Kriteria reliabilitas mempergunakan koefisien reliabilitas Alpha dari Cronbach dengan cara menghitung masing masing reliabilitas ( $\mathrm{r}$ hitung) tiap variable dan memasukan hasilnya kedalam kategori yang telah ditetapkan (Alpha Cronbach) Tabel 4.

Tabel 4 reliabilitas Alpha Cronbach 
Ike Septiani, Sumardi HR, Suryanti

\begin{tabular}{|c|c|c|c|c|c|c|c|c|c|c|c|c|c|c|}
\hline variable & \multicolumn{6}{|c|}{ Kinerja } & \multicolumn{4}{|c|}{ Motivasi } & \multicolumn{4}{|c|}{ Lingkungan Kerja } \\
\hline Indikator & 1 & 2 & 3 & 4 & 5 & 6 & 1 & 2 & 3 & 4 & 1 & 2 & 3 & 4 \\
\hline $\begin{array}{l}\text { Jumlah } \\
\text { butir }\end{array}$ & 2 & 2 & 2 & 2 & 2 & 2 & 2 & 2 & 2 & 2 & 2 & 2 & 2 & 2 \\
\hline $\begin{array}{l}\text { Rata2 } \\
\text { indikator }\end{array}$ & $\begin{array}{c}0,8 \\
6\end{array}$ & 0,80 & 0,87 & 0,81 & 0,89 & 0,87 & 0,76 & 0,81 & 0,80 & 0,83 & 0,85 & 0,83 & 0,81 & 0,8 \\
\hline $\begin{array}{c}\text { Rerata } \\
\text { Variabel }\end{array}$ & \multicolumn{6}{|c|}{0,855} & \multicolumn{4}{|c|}{0,801} & \multicolumn{4}{|c|}{0,824} \\
\hline $\begin{array}{l}\text { Indikator } \\
\text { terendah }\end{array}$ & \multicolumn{6}{|c|}{ 2. Kuantitas (jumlah) $(0,80)$} & \multicolumn{4}{|c|}{ 1. Bekerja sama $(0,76)$} & \multicolumn{4}{|c|}{ 4. Suasana kerja $(0.8)$} \\
\hline $\begin{array}{l}\text { Indikator } \\
\text { tertinggi }\end{array}$ & \multicolumn{6}{|c|}{ 5. Pengawasan $(0,89)$} & \multicolumn{4}{|c|}{ 4. Semangat Kerja $(0,83)$} & \multicolumn{4}{|c|}{ 1. Sarana dan Prasarana (0.85) } \\
\hline $\begin{array}{l}\text { Butir } \\
\text { (item) } \\
\text { terendah }\end{array}$ & \multicolumn{6}{|c|}{$\begin{array}{l}\text { 4. Pegawai mampu menyelesaikan } \\
\text { setiap pekerjaan dengan.... }(0,8)\end{array}$} & \multicolumn{4}{|c|}{$\begin{array}{l}\text { 1. Saya mampu bekerja } \\
\text { sama dengan pegawai } \\
\text { lainnya }(0,75)\end{array}$} & \multicolumn{4}{|c|}{$\begin{array}{l}\text { 7. Kenyamanan dalam bekerja } \\
(0,78)\end{array}$} \\
\hline $\begin{array}{l}\text { Butir } \\
\text { (item) } \\
\text { tertinggi }\end{array}$ & \multicolumn{6}{|c|}{$\begin{array}{l}\text { 9. Pegawai tersebut mampu bekerja } \\
\text { tanpa melakukan penyimpangan } \\
\text { dengan... }(0,92)\end{array}$} & \multicolumn{4}{|c|}{$\begin{array}{l}\text { 8. Saya mampu bekerja } \\
\text { dengan sungguh-sungguh } \\
(0.87)\end{array}$} & \multicolumn{4}{|c|}{ 1. Kondisi sarana kantor $(0,87)$} \\
\hline
\end{tabular}

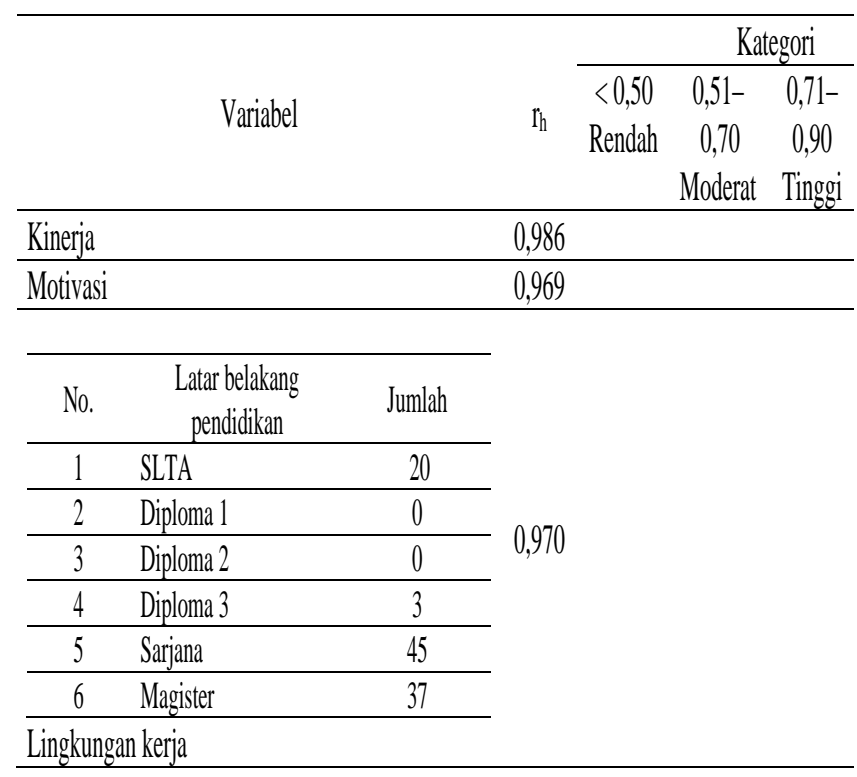

Penelitian ini mempunyai tiga variabel yaitu variable; Kinerja (Y) sebagai variable terikat, sedangkan Motivasi $\left(\mathrm{X}_{1}\right)$ dan Lingkungan kerja $\left(\mathrm{X}_{2}\right)$ sebagai variabel bebas. Konstalasi penelitian simultan (berganda) yang tergambar pada Gambar 1.

Gambar 1 Konstalasi Penelitian

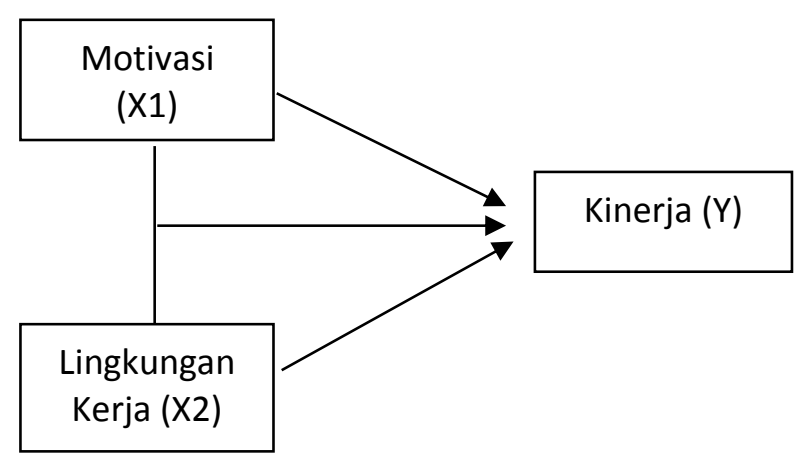

Responden adalah pegawai Dinas Pendidikan Kabupaten Indramayu memiliki latar belakang pendidikan seperti yang tergambar pada Tabel 1 . 
Ike Septiani, Sumardi HR, Suryanti

\section{Analisis Korelasi}

Analisis Korelasi Motivasi Terhadap Kinerja Hasil perhitungan korelasi Motivasi terhadap Kinerja menggunakan rumus Produk Moment Pearson sebagai berikut :

$$
r=\frac{\mathrm{n} \sum \mathrm{xy}-\left(\sum \mathrm{x}\right)\left(\sum \mathrm{y}\right)}{\sqrt{\left\{\mathrm{n} \sum \mathrm{x}^{2}-\left(\sum \mathrm{x}\right)^{2}\left\{\mathrm{n} \sum \mathrm{y}^{2}-\left(\sum \mathrm{y}\right)^{2}\right\}\right.}}
$$

r

$$
=\frac{83 \times 137044-(2662)(4259)}{\sqrt{\left(83 \times 87284-(2662)^{2}\right)\left(83 \times 220675-(4259)^{2}\right)}}
$$$$
r=\frac{11374652-11337458}{\sqrt{(7244572-7086244)(18316025-18139081)}}
$$

$$
\begin{aligned}
& r=\frac{37194}{\sqrt{158328 \times 176944}} \\
& r=\frac{37194}{167377}=0,222
\end{aligned}
$$

Dari perhitungan korelasi diatas dapat disimpulkan bahwa nilai $r$ hitung sebesar 0,222 termasuk kategori

\section{rendah}

Analisis Korelasi Lingkungan Kerja Terhadap

\section{Kinerja}

Hasil perhitungan korelasi Lingkungan Kerja terhadap Kinerja menggunakan rumus Produk Moment Pearson sebagai berikut:

$$
\begin{gathered}
r=\frac{\mathrm{n} \sum \mathrm{xy}-\left(\sum \mathrm{x}\right)\left(\sum \mathrm{y}\right)}{\sqrt{\left\{\mathrm{n} \Sigma \mathrm{x}^{2}-\left(\sum \mathrm{x}\right)^{2}\left\{\mathrm{n} \Sigma \mathrm{y}^{2}-(\Sigma \mathrm{y})^{2}\right\}\right.}} \\
\mathrm{r}=\frac{83 \times 141072-(2736)(4259)}{\sqrt{\left(83.91724-(2736)^{2}\right)\left(83.220675-(4259)^{2}\right)}}
\end{gathered}
$$

$$
r=\frac{11708976-11652624}{\sqrt{(7613092-7485696)(18316025-18139081)}}
$$

$$
\mathrm{rc}=\frac{56343}{\sqrt{127396 \times 176944}}
$$

$$
r=\frac{56343}{150139,79}=0,375
$$

Dari perhitungan korelasi diatas dapat disimpulkan bahwa nilai $r$ hitung sebesar 0,375 termasuk kategori rendah.

Analisis Korelasi Motivasi Terhadap Lingkungan Kerja

Hasil perhitungan korelasi Motivasi terhadap Lingkungan kerja menggunakan rumus Produk Moment Pearson sebagai berikut

$$
\begin{gathered}
r=\frac{\mathrm{n} \sum \mathrm{x} 1 \mathrm{x} 2-\left(\sum \mathrm{x} 1\right)\left(\sum \mathrm{x} 2\right)}{\sqrt{\left\{\mathrm{n} \sum \mathrm{x} 1^{2}-\left(\sum \mathrm{x} 1\right)^{2}\left\{\mathrm{n} \sum \mathrm{x}^{2}-\left(\sum \mathrm{x} 2\right)^{2}\right\}\right.}} \\
\mathrm{r}=\frac{83 \times 88126-(2662)(2736)}{\sqrt{\left(83 \times 87284-(2662)^{2}\right)\left(83 \times 91724-(2736)^{2}\right)}} \\
\mathrm{r}=\frac{7314458-7283232}{\sqrt{(7244572-7086244)(7613092-7485696)}} \\
r=\frac{31226}{142022,37}=0,219
\end{gathered}
$$

Dari perhitungan korelasi diatas dapat disimpulkan bahwa nilai $\mathrm{r}$ hitung sebesar 0,219 termasuk kategori rendah.

Analisis Koefisien Korelasi Motivasi dan Lingkungan Kerja Terhadap Kinerja 
Ike Septiani, Sumardi HR, Suryanti

Korelasi ganda merupakan angka yang menunjukan arah dan kuatnya hubungan antara dua variabel independen secara bersama-sama atau lebih dari satu variabel dependen. Jadi analisis korelasi ganda bertujuan untuk mengetahui koefisien korelasi antara variabel Motivasi (X1) dan Lingkungan Kerja (X2) terhadap Kinerja (Y) secara simultan atau bersama-sama. Rumus yang digunakan sebagai berikut :

$\operatorname{Ryx} 1 \mathrm{x} 2=\frac{\sqrt{\text { ryx }^{2}+\operatorname{ryx}^{2}-2 \operatorname{ryx} 1 \cdot \operatorname{ryx} 2 \cdot \operatorname{rx} 1 \times 2}}{1-\operatorname{rx} 1 \times 2^{2}}$

$\operatorname{Ryx} 1 x 2=\sqrt{\frac{(0,222)^{2}+(0,375)^{2}-2 \cdot(0,222) \cdot(0,375) \cdot(0,219)}{1-(0,219)^{2}}}$

$\operatorname{Ryx} 1 x 2=\sqrt{\frac{(0,190)-(0,036)}{(0,952)}}$

$\operatorname{Ryx} 1 x 2=\sqrt{\frac{0,154}{0,952}}$

$\operatorname{Ryx} 1 \times 2=\sqrt{0,1609}=0,401$

Dari hasil perhitungan diatas diperoleh koefisien korelasi sebesar $\mathbf{0 . 4 0 1}$ yang termasuk kategori Sedang

\section{Gambar 4}

\section{Analisis Penelitian}

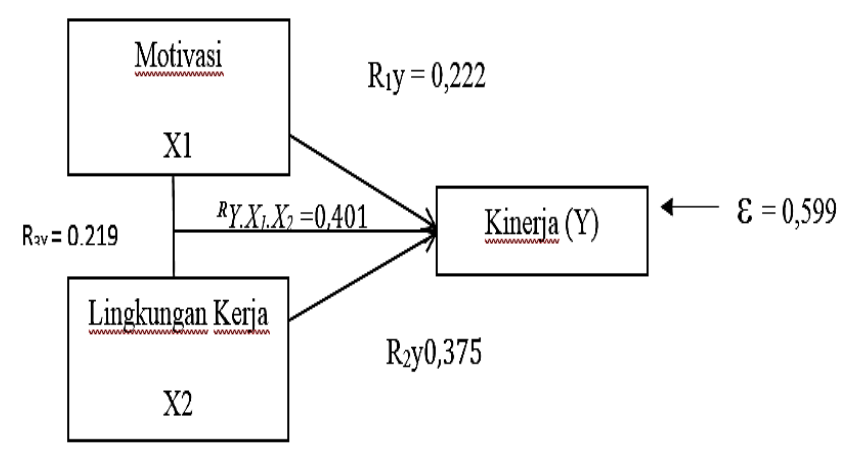

\section{KESIMPULAN DAN SARAN}

Kesimpulan
Dari hasil uraian diatas, serta hasil pembahasan yang peneliti lakukan tentang pengaruh Motivasi dan Lingkungan Kerja terhadap Kinerja di Dinas Pendidikan Kabupaten Indramayu, maka peneliti mengambil kesimpulan sebagai berikut :

1. Kinerja Pegawai Dinas Pendidikan Kabupaten Indramayu termasuk kedalam kategori Sangat Baik.

2. Motivasi Pegawai Dinas Pendidikan Kabupaten Indramayu termasuk kedalam kategori Baik.

3. Lingkungan Kerja Pegawai Dinas Pendidikan Kabupaten Indramayu termasuk kedalam kategori Sangat Baik.

4. Motivasi berpengaruh langsung dan posistif terhadap Kinerja Pegawai Dinas Pendidikan Kabupaten Indramayu termasuk kedalam kategori rendah.

5. Lingkungan Kerja berpengaruh langsung dan posistif terhadap Kinerja Pegawai Dinas Pendidikan Kabupaten Indramayu termasuk kedalam kategori rendah.

6. Motivasi dan Lingkungan Kerja berpengaruh langsung dan posistif terhadap Kinerja Pegawai Dinas Pendidikan Kabupaten Indramayu termasuk kedalam kategori sedang.

Saran

Dari hasil kesimpulan diatas peneliti mengemukakan beberapa saran sebagai berikut:

1. Untuk dapat mempertahankan Kinerja Pegawai Dinas Pendidikan Kabupaten 
Ike Septiani, Sumardi HR, Suryanti

Indramayu disarankan kepada pegawai

Dinas Pendidikan Kabupaten

Indramayu untuk lebih ditingkatkan lagi kuantitas (jumlah) kerjanya.

2. Untuk dapat mempertahankan Motivasi Pegawai Dinas Pendidikan Kabupaten Indramayu disarankan agar meningkatkan bekerja sama antar pegawai satu dengan pegawai lainnya sehingga memberikan kerja sama yang baik.

3. Untuk dapat mempertahankan Lingkungan Kerja Pegawai Dinas Pendidikan Kabupaten Indramayu agar lebih ditingkatkan lagi hubungan kerja antar pegawai maupun pegawai dengan pimpinan agar dapat mempererat hubungan kerja yang baik.

\section{DAFTAR PUSTAKA}

Anwar Prabu Mangkunegara. 2016.

Manajemen Sumber Daya Manusia Perusahaan. Bandung : Remaja Rosdakarya

Alex S. Nitisemito. 2015. Manajemen Personalia. Jakarta : Ghalia Indonesia

Edy Sutrisno. 2017. Manajemen Sumber Daya Manusia. Jakarta : Kencana

Emron, Yohny dan Imas. 2017. Manajemen Sumber Daya Manusia. Bandung : Alfabeta

Irham Fahmi. 2017. Manajemen Sumber Daya Manusia Teori dan Aplikasi. Bandung : Alfabeta
Kasmir. 2016. Manajemen Sumber Daya Manusia (Teori dan Praktik). Jakarta : RajaGrafindo Persada

Lijan Poltak Sinambela. 2016. Manajemen Sumber Daya Manusia : Membangun tim kerja yang solid untuk Meningkatkan Kinerja. Jakarta : Bumi Aksara

Muhammad Busro. 2018. Teori - teori Manajemen Sumber Daya Manusia. Jakarta : Prenadamedia Group

Sugiono. 2017. Statistika Untuk Penelitian. Bandung : Alfabeta

Wibowo. 2016. Manajemen Kinerja. Jakarta : RajaGrafindo Persada 